\title{
Multivalued fixed point theorems in tvs-cone metric spaces
}

\author{
Akbar Azam* and Nayyar Mehmood
}

"Correspondence:

akbarazam@yahoo.com

Department of Mathematics, COMSATS Institute of Information

Technology, Chak Shahzad, Islamabad 44000, Pakistan

\begin{abstract}
In this paper we extend the Kannan, Chatterjea and Zamfirescu theorems for multivalued mappings in a tvs-cone metric space without the assumption of normality on cones and generalize many results in literature.
\end{abstract}

MSC: $47 \mathrm{H} 10 ; 54 \mathrm{H} 25$

Keywords: tvs-cone metric space; non-normal cones; multivalued contraction; fixed points

\section{Introduction}

The notion of cone metric space was introduced by Huang and Zhang in [1]. They replaced the set of real numbers by an ordered Banach space and defined a cone metric space. They extended Banach fixed point theorems for contractive type mappings. Many authors [225] studied the properties of cone metric spaces and generalized important fixed point results of complete metric spaces. The concept of cone metric space in the sense of HuangZhang was characterized by Al-Rawashdeh et al. in [26]. Indeed, $(X, d)$ is a cone metric space if and only if $\left(X, d^{E}\right)$ is an $E$-metric space, where $E$ is a normed ordered space, with $\operatorname{int}\left(E^{+}\right) \neq \phi([26]$, Theorem 3.8).

Recently Beg et al. [27] introduced and studied topological vector space-valued cone metric spaces (tvs-cone metric spaces), which generalized the cone metric spaces [1].

Let $(X, d)$ be a metric space. A mapping $T: X \rightarrow X$ is called a contraction if there exists $\lambda \in[0,1)$ such that

$$
d(T x, T y) \leq \lambda d(x, y)
$$

for all $x, y \in X$. A mapping $T$ is called Kannan if there exists $\alpha \in\left[0, \frac{1}{2}\right)$ such that

$$
d(T x, T y) \leq \alpha[d(x, T x)+d(y, T y)]
$$

The main difference between contraction and Kannan mappings is that contractions are always continuous, whereas Kannan mappings are not necessarily continuous. Another type of contractive condition, due to Chatterjea [28], is based on an assumption analogous to Kannan mappings as follows: there exists $\alpha \in\left[0, \frac{1}{2}\right)$ such that

$$
d(T x, T y) \leq \alpha[d(x, T y)+d(y, T x)]
$$

(O) 2013 Azam and Mehmood; licensee Springer. This is an Open Access article distributed under the terms of the Creative Commons Attribution License (http://creativecommons.org/licenses/by/2.0), which permits unrestricted use, distribution, and reproduction in any medium, provided the original work is properly cited. 
It is well known that the Banach contractions, Kannan mappings and Chatterjea mappings are independent in general. Zamfirescu [29] proved a remarkable fixed point theorem by combining the results of Banach, Kannan and Chatterjea. Afterwards, some authors investigated these results in many directions [29-34].

In the papers [35-39], the authors studied fixed point theorems for multivalued mappings in cone metric spaces. Seong and Jong [35] invented the generalized Hausdorff distance in a cone metric space and proved multivalued results in cone metric spaces. Shatanawi et al. [39] generalized it in the case of tvs-cone metric spaces. However, all these results presented in the literature [35-39] for the case of multivalued mappings in cone metric spaces are restricted to Banach contraction. In this paper, we have achieved the results for Kannan and Chatterjea contraction for multivalued mappings in tvs-cone metric spaces. We also extend the Zamfirescu theorem to multivalued mappings in tvscone metric spaces.

\section{Preliminaries}

Let $\mathbb{E}$ be a topological vector space with its zero vector $\theta$. A nonempty subset $P$ of $\mathbb{E}$ is called a convex cone if $P+P \subseteq P$ and $\lambda P \subseteq P$ for $\lambda \geq 0$. A convex cone $P$ is said to be pointed (or proper) if $P \cap(-P)=\{\theta\}$; and $P$ is normal (or saturated) if $\mathbb{E}$ has a base of neighborhoods of zero consisting of order-convex subsets. For a given cone $P \subseteq \mathbb{E}$, we define a partial ordering $\preccurlyeq$ with respect to $P$ by $x \preccurlyeq y$ if and only if $y-x \in P ; x \prec y$ stands for $x \preccurlyeq y$ and $x \neq y$, while $x \ll y$ stands for $y-x \in \operatorname{int} P$, where int $P$ denotes the interior of $P$. The cone $P$ is said to be solid if it has a nonempty interior.

Now let us recall the following definitions and remarks.

Definition 2.1 [27] Let $X$ be a nonempty set, and let $(\mathbb{E}, P)$ be an ordered tvs. A vectorvalued function $d: X \times X \rightarrow \mathbb{E}$ is said to be a tvs-cone metric if the following conditions hold:

(C1) $\theta \preccurlyeq d(x, y)$ for all $x, y \in X$ and $d(x, y)=\theta$ if and only if $x=y$;

(C2) $d(x, y)=d(y, x)$ for all $x, y \in X$;

(C3) $d(x, z) \preccurlyeq d(x, y)+d(y, z)$ for all $x, y, z \in X$.

The pair $(X, d)$ is then called a tvs-cone metric space.

Remark 2.1 [27] The concept of cone metric space is more general than that of metric space, because each metric space is a cone metric space, and a cone metric space in the sense of Huang and Zhang is a special case of tvs-cone metric spaces when $(X, d)$ is a tvs-cone metric space with respect to a normal cone $P$.

Definition 2.2 [27] Let $(X, d)$ be a tvs-cone metric space, $x \in X$, and let $\left\{x_{n}\right\}$ be a sequence in $X$. Then

(i) $\left\{x_{n}\right\}$ tvs-cone converges to $x$ if for every $c \in \mathbb{E}$ with $\theta \ll c$ there is a natural number $n_{0}$ such that $d\left(x_{n}, x\right) \ll c$ for all $n \geq n_{0}$. We denote this by cone- $\lim _{n \rightarrow \infty} x_{n}=x$;

(ii) $\left\{x_{n}\right\}$ is a tvs-cone Cauchy sequence if for every $c \in \mathbb{E}$ with $\theta \ll c$ there is a natural number $n_{0}$ such that $d\left(x_{n}, x_{m}\right) \ll c$ for all $n, m \geq n_{0}$;

(iii) $(X, d)$ is tvs-cone complete if every tvs-cone Cauchy sequence in $X$ is tvs-cone convergent. 
Remark 2.2 [16] The results concerning fixed points and other results, in the case of cone spaces with non-normal solid cones, cannot be provided by reducing to metric spaces, because in this case neither of the conditions of Lemmas 1-4 in [1] hold. Further, the vector cone metric is not continuous in the general case, i.e., from $x_{n} \rightarrow x, y_{n} \rightarrow y$ it need not follow that $d\left(x_{n}, y_{n}\right) \rightarrow d(x, y)$.

Let $(X, d)$ be a tvs-cone metric space. The following properties will be used very often (for more details, see [16, 39]).

(PT1) If $u \preccurlyeq v$ and $v \ll w$, then $u \ll w$.

(PT2) If $u \ll v$ and $v \preccurlyeq w$, then $u \ll w$.

(PT3) If $u \ll v$ and $v \ll w$, then $u \ll w$.

(PT4) If $\theta \preccurlyeq u \ll c$ for each $c \in \operatorname{int} P$, then $u=\theta$.

(PT5) If $a \preccurlyeq b+c$ for each $c \in \operatorname{int} P$, then $a \preccurlyeq b$.

(PT6) If $\mathbb{E}$ is a tvs-cone metric space with a cone $P$, and if $a \preccurlyeq \lambda a$, where $a \in P$ and $0 \leq \lambda<1$, then $a=\theta$.

(PT7) If $c \in \operatorname{int} P, a_{n} \in \mathbb{E}$ and $a_{n} \rightarrow \theta$ in locally convex Hausdorff tvs $\mathbb{E}$, then there exists an $n_{0}$ such that, for all $n>n_{0}$, we have $a_{n} \ll c$.

\section{Main result}

In the sequel, $\mathbb{E}$ denotes a locally convex Hausdorff topological vector space with its zero vector $\theta, P$ is a proper, closed and convex pointed cone in $\mathbb{E}$ with int $P \neq \emptyset$, and $\preccurlyeq$ denotes the induced partial ordering with respect to $P$.

Let $(X, d)$ be a tvs-cone metric space with a solid cone $P$, and let $\Lambda$ be a collection of nonempty subsets of $X$. Let $T: X \rightarrow \Lambda$ be a multivalued map. For $x \in X, A \in \Lambda$, define

$$
W_{x}(A)=\{d(x, a): a \in A\}
$$

Thus, for $x, y \in X$,

$$
W_{x}(T y)=\{d(x, u): u \in T y\} .
$$

Definition 3.1 [11] Let $(X, d)$ be a cone metric space with a solid cone $P$. A set-valued mapping $F: X \rightarrow 2^{\mathbb{E}}$ is called bounded from below if for all $x \in X$ there exists $z(x) \in \mathbb{E}$ such that

$$
F x-z(x) \subset P .
$$

Definition 3.2 [11] Let $(X, d)$ be a cone metric space with a solid cone $P$. The cone $P$ is complete if for every bounded above nonempty subset $A$ of $\mathbb{E}, \sup A$ exists in $\mathbb{E}$. Equivalently, the cone $P$ is complete if for every bounded below nonempty subset $A$ of $\mathbb{E}, \inf A$ exists in $\mathbb{E}$.

Definition 3.3 Let $(X, d)$ be a tvs-cone metric space with a solid cone $P$. The multivalued mapping $T: X \rightarrow \Lambda$ is said to have lower bound property (l.b. property) on $X$ if, for any $x \in X$, the multivalued mapping $F_{x}: X \rightarrow 2^{\mathbb{E}}$, defined by

$$
F_{x}(y)=W_{x}(T y),
$$


is bounded from below. That is, for $x, y \in X$, there exists an element $\ell_{x}(T y) \in \mathbb{E}$ such that

$$
W_{x}(T y)-\ell_{x}(T y) \subset P .
$$

An $\ell_{x}(T y)$ is called lower bound of $T$ associated with $(x, y)$. By $L_{x y}(T)$ we denote the set of all lower bounds $T$ associated with $(x, y)$. Moreover, $\bigcup_{x, y \in X} L_{x y}(T)$ is denoted by $L_{X}(T)$.

Definition 3.4 Let $(X, d)$ be a tvs-cone metric space with a solid cone $P$. The multivalued mapping $T: X \rightarrow \Lambda$ is said to have greatest lower bound property (g.l.b. property) on $X$ if the greatest lower bound of $W_{x}(T y)$ exists in $\mathbb{E}$ for all $x, y \in X$.

We denote by $d(x, T y)$ the greatest lower bound of $W_{x}(T y)$. That is,

$$
d(x, T y)=\inf \{d(x, u): u \in T y\} .
$$

According to [39], let us denote

$$
s(p)=\{q \in \mathbb{E}: p \preccurlyeq q\} \text { for } q \in \mathbb{E}
$$

and

$$
s(a, B)=\bigcup_{b \in B} s(d(a, b))=\bigcup_{b \in B}\{x \in \mathbb{E}: d(a, b) \preccurlyeq x\} \quad \text { for } a \in X \text { and } B \in \Lambda \text {. }
$$

For $A, B \in \Lambda$, we denote

$$
s(A, B)=\left(\bigcap_{a \in A} s(a, B)\right) \cap\left(\bigcap_{b \in B} s(b, A)\right) .
$$

Let us recall the following lemma, which will be used to prove our main Theorem 3.1.

Lemma 3.1 [39] Let $(X, d)$ be a tvs-cone metric space with a solid cone P in ordered locally convex space $\mathbb{E}$. Then we have:

(i) Let $p, q \in \mathbb{E}$. If $p \preccurlyeq q$, then $s(q) \subset s(p)$.

(ii) Let $x \in X$ and $A \in \Lambda$. If $\theta \in s(x, A)$, then $x \in A$.

(iii) Let $q \in P$ and let $A, B \in \Lambda$ and $a \in A$. If $q \in s(A, B)$, then $q \in s(a, B)$.

(iv) For all $q \in P$ and $A, B \in \Lambda$. Then $q \in s(A, B)$ if and only if there exist $a \in A$ and $b \in B$ such that $d(a, b) \preccurlyeq q$.

Remark 3.1 [39] Let $(X, d)$ be a tvs-cone metric space. If $\mathbb{E}=R$ and $P=[0,+\infty)$, then $(X, d)$ is a metric space. Moreover, for $A, B \in C B(X), H(A, B)=\inf s(A, B)$ is the Hausdorff distance induced by $d$. Also, $s(\{x\},\{y\})=s(d(x, y))$ for all $x, y \in X$.

Now, let us prove the following result which is a Kannan-type multivalued theorem in tvs-cone metric spaces.

Theorem 3.1 Let $(X, d)$ be a complete tvs-cone metric space with a cone $P$, let $\Lambda \neq \phi$ be a collection of nonempty closed subsets of $X$, and let $T: X \rightarrow \Lambda$ be a multivalued mapping 
having l.b. property. If for $x, y \in X$ there exist $\ell_{x}(T x), \ell_{y}(T y) \in L_{X}(T)$ and $k \in\left[0, \frac{1}{2}\right)$ such that

$$
k\left[\ell_{x}(T x)+\ell_{y}(T y)\right] \in s(T x, T y),
$$

then $T$ has a fixed point in $X$.

Proof Let $x_{0}$ be an arbitrary point in $X$ and $x_{1} \in T x_{0}$. By assumptions,

$$
k\left[\ell_{x_{0}}\left(T x_{0}\right)+\ell_{x_{1}}\left(T x_{1}\right)\right] \in s\left(T x_{0}, T x_{1}\right) .
$$

If $k=0$, then

$$
\theta \in s\left(T x_{0}, T x_{1}\right)
$$

Thus, by Lemma 3.1(iii),

$$
\theta \in s\left(x_{1}, T x_{1}\right)=\bigcup_{x \in T x_{1}} s\left(d\left(x_{1}, x\right)\right)
$$

Thus, there exists some $x_{2} \in T x_{1}$ such that

$$
\theta \in s\left(d\left(x_{1}, x_{2}\right)\right)
$$

Thus

$$
d\left(x_{1}, x_{2}\right)=\theta
$$

Hence $x_{1} \in T x_{1}$. Now assume that $k \neq 0$. Then, by Lemma 3.1(iii), we obtain

$$
k\left[\ell_{x_{0}}\left(T x_{0}\right)+\ell_{x_{1}}\left(T x_{1}\right)\right] \in s\left(x_{1}, T x_{1}\right) .
$$

Thus, there exists some $x_{2} \in T x_{1}$ such that

$$
k\left[\ell_{x_{0}}\left(T x_{0}\right)+\ell_{x_{1}}\left(T x_{1}\right)\right] \in s\left(d\left(x_{1}, x_{2}\right)\right) .
$$

Thus

$$
d\left(x_{1}, x_{2}\right) \preccurlyeq k\left[\ell_{x_{0}}\left(T x_{0}\right)+\ell_{x_{1}}\left(T x_{1}\right)\right] .
$$

As

$$
W_{x_{0}}\left(T x_{0}\right)-\ell_{x_{0}}\left(T x_{0}\right) \subset P, \quad W_{x_{1}}\left(T x_{1}\right)-\ell_{x_{1}}\left(T x_{1}\right) \subset P .
$$

It yields, $\ell_{x_{0}}\left(T x_{0}\right) \preccurlyeq d\left(x_{0}, x_{1}\right), \ell_{x_{1}}\left(T x_{1}\right) \preccurlyeq d\left(x_{1}, x_{2}\right)$, thus

$$
d\left(x_{1}, x_{2}\right) \preccurlyeq k\left[d\left(x_{0}, x_{1}\right)+d\left(x_{1}, x_{2}\right)\right] .
$$


Again, by Lemma 3.1(iii), we obtain

$$
k\left[\ell_{x_{1}}\left(T x_{1}\right)+\ell_{x_{2}}\left(T x_{2}\right)\right] \in s\left(x_{2}, T x_{2}\right) .
$$

Thus, we can choose $x_{3} \in T x_{2}$ such that

$$
k\left[\ell_{x_{1}}\left(T x_{1}\right)+\ell_{x_{2}}\left(T x_{2}\right)\right] \in s\left(d\left(x_{2}, x_{3}\right)\right) .
$$

Then

$$
d\left(x_{2}, x_{3}\right) \preccurlyeq k\left[\ell_{x_{1}}\left(T x_{1}\right)+\ell_{x_{2}}\left(T x_{2}\right)\right] .
$$

Again, using the fact

$$
W_{x_{i}}\left(T x_{i}\right)-\ell_{x_{i}}\left(T x_{i}\right) \subset P, \quad i=1,2,
$$

we have

$$
d\left(x_{2}, x_{3}\right) \preccurlyeq k\left[d\left(x_{1}, x_{2}\right)+d\left(x_{2}, x_{3}\right)\right] .
$$

By mathematical induction, we construct a sequence $\left\{x_{n}\right\}$ in $X$ such that

$$
d\left(x_{n}, x_{n+1}\right) \preccurlyeq k\left[d\left(x_{n-1}, x_{n}\right)+d\left(x_{n}, x_{n+1}\right)\right], \quad x_{n+1} \in T x_{n} \text { for } n=0,1,2,3, \ldots
$$

It follows that

$$
\begin{aligned}
d\left(x_{n}, x_{n+1}\right) & \preccurlyeq \frac{k}{1-k} d\left(x_{n-1}, x_{n}\right) \\
& \preccurlyeq \eta\left(d x_{n-1}, x_{n}\right) \\
& \prec \eta^{2} d\left(x_{n-2}, x_{n-3}\right) \prec \cdots \prec \eta^{n} d\left(x_{0}, x_{1}\right),
\end{aligned}
$$

where $\eta=\frac{k}{1-k}$. Now, for $m>n$, this gives

$$
d\left(x_{n}, x_{m}\right) \preccurlyeq \frac{\eta^{n}}{1-\eta} d\left(x_{0}, x_{1}\right)
$$

Since $\eta^{n} \rightarrow 0$ as $n \rightarrow \infty$, this gives us $\frac{\eta^{n}}{1-\eta} d\left(x_{0}, x_{1}\right) \rightarrow \theta$ in the locally convex space $\mathbb{E}$ as $n \rightarrow \infty$. Now, according to (PT7) and (PT1), we can conclude that for every $c \in \mathbb{E}$ with $\theta \ll c$, there is a natural number $n_{1}$ such that $d\left(x_{n}, x_{m}\right) \ll c$ for all $m, n \geq n_{1}$, so $\left\{x_{n}\right\}$ is a tvs-cone Cauchy sequence. As $(X, d)$ is tvs-cone complete, $\left\{x_{n}\right\}$ is tvs-cone convergent in $X$ and cone- $\lim _{n \rightarrow \infty} x_{n}=v$. Hence, for every $c \in \mathbb{E}$ with $\theta \ll c$, there is a natural number $k_{1}$ such that

$$
\frac{2}{1-k} d\left(x_{n}, v\right) \ll c, \quad \frac{2 k}{1-k} d\left(x_{n}, x_{n+1}\right) \ll c \quad \text { for all } n \geq k_{1} .
$$

We now show that $v \in T v$. Consider

$$
k\left[\ell_{x_{n}}\left(T x_{n}\right)+\ell_{v}(T v)\right] \in s\left(T x_{n}, T v\right) .
$$


As $x_{n+1} \in T x_{n}$, therefore, it follows that

$$
k\left[\ell_{x_{n}}\left(T x_{n}\right)+\ell_{v}\left(T x_{v}\right)\right] \in s\left(x_{n+1}, T v\right) .
$$

So there exists $u_{n} \in T v$ such that

$$
k\left[\ell_{x_{n}}\left(T x_{n}\right)+\ell_{v}\left(T x_{v}\right)\right] \in s\left(d\left(x_{n+1}, u_{n}\right)\right),
$$

which implies that

$$
\begin{aligned}
d\left(x_{n+1}, u_{n}\right) & \preccurlyeq k\left[\ell_{x_{n}}\left(T x_{n}\right)+\ell_{v}\left(T x_{v}\right)\right] \\
& \preccurlyeq k\left[d\left(x_{n}, x_{n+1}\right)+d\left(v, u_{n}\right)\right] .
\end{aligned}
$$

Therefore, by (3.1),

$$
\begin{aligned}
d\left(v, u_{n}\right) & \preccurlyeq d\left(x_{n+1}, v\right)+d\left(x_{n+1}, u_{n}\right) \\
& \preccurlyeq d\left(x_{n+1}, v\right)+k\left[d\left(x_{n}, x_{n+1}\right)+d\left(v, u_{n}\right)\right] \\
& \preccurlyeq \frac{1}{1-k} d\left(x_{n+1}, v\right)+\frac{k}{1-k} d\left(x_{n}, x_{n+1}\right) \\
& \preccurlyeq \frac{2}{1-k} \frac{d\left(x_{n+1}, v\right)}{2}+\frac{2 k}{1-k} \frac{d\left(x_{n}, x_{n+1}\right)}{2} \\
& \ll c \text { for all } n \geq k_{1}=k_{1}(c) .
\end{aligned}
$$

Hence, cone- $\lim _{n \rightarrow \infty} u_{n}=v$. Since $T v$ is closed, so $v \in T v$.

In the following we provide a Chatterjea-type multivalued theorem in a tvs-cone metric space.

Theorem 3.2 Let $(X, d)$ be a complete tvs-cone metric space with a cone $P$, let $\Lambda \neq \phi$ be a collection of nonempty closed subsets of $X$, and let $T: X \rightarrow \Lambda$ be a multivalued mapping. If for $x, y \in X$, there exist $\ell_{x}(T y), \ell_{y}(T x) \in L_{X}(T)$ and $k \in\left[0, \frac{1}{2}\right)$ such that

$$
k\left[\ell_{x}(T y)+\ell_{y}(T x)\right] \in s(T x, T y),
$$

then $T$ has a fixed point in $X$.

Proof If $k=0$, there is nothing to prove. Let $k \neq 0$ and $x_{0}$ be an arbitrary point in $X$, choose $x_{1} \in T x_{0}$. Consider by assumption

$$
k\left[\ell_{x_{0}}\left(T x_{1}\right)+\ell_{x_{1}}\left(T x_{0}\right)\right] \in s\left(T x_{0}, T x_{1}\right) .
$$

This implies that

$$
k\left[\ell_{x_{0}}\left(T x_{1}\right)+\ell_{x_{1}}\left(T x_{0}\right)\right] \in s\left(x, T x_{1}\right) \quad \text { for all } x \in T x_{0} .
$$


As $x_{1} \in T x_{0}$, so we have

$$
k\left[\ell_{x_{0}}\left(T x_{1}\right)+\ell_{x_{1}}\left(T x_{0}\right)\right] \in s\left(x_{1}, T x_{1}\right) .
$$

Then we can find $x_{2} \in T x_{1}$ such that

$$
k\left[\ell_{x_{0}}\left(T x_{1}\right)+\ell_{x_{1}}\left(T x_{0}\right)\right] \in s\left(d\left(x_{1}, x_{2}\right)\right) .
$$

Thus

$$
d\left(x_{1}, x_{2}\right) \preccurlyeq k\left[\ell_{x_{0}}\left(T x_{1}\right)+\ell_{x_{1}}\left(T x_{0}\right)\right]
$$

Since

$$
W_{x_{0}}\left(T x_{1}\right)-\ell_{x_{0}}\left(T x_{1}\right) \subset P, \quad W_{x_{1}}\left(T x_{0}\right)-\ell_{x_{1}}\left(T x_{0}\right) \subset P,
$$

therefore

$$
\begin{aligned}
d\left(x_{1}, x_{2}\right) & \preccurlyeq k\left[d\left(x_{0}, x_{2}\right)+d\left(x_{1}, x_{1}\right)\right] \\
& \preccurlyeq k\left[d\left(x_{0}, x_{1}\right)+d\left(x_{1}, x_{2}\right)\right] \\
& \preccurlyeq \frac{k}{1-k} d\left(x_{0}, x_{1}\right) .
\end{aligned}
$$

By the same argument we can choose $x_{3} \in T x_{2}$ such that

$$
k\left[\ell_{x_{1}}\left(T x_{2}\right)+\ell_{x_{2}}\left(T x_{1}\right)\right] \in s\left(d\left(x_{2}, x_{3}\right)\right) .
$$

Then

$$
d\left(x_{2}, x_{3}\right) \preccurlyeq k\left[\ell_{x_{1}}\left(T x_{2}\right)+\ell_{x_{2}}\left(T x_{1}\right)\right] .
$$

Again, using the fact

$$
W_{x_{1}}\left(T x_{2}\right)-\ell_{x_{1}}\left(T x_{2}\right) \subset P, \quad W_{x_{2}}\left(T x_{1}\right)-\ell_{x_{2}}\left(T x_{1}\right) \subset P,
$$

we have

$$
\begin{aligned}
d\left(x_{2}, x_{3}\right) & \preccurlyeq k\left[d\left(x_{1}, x_{3}\right)+d\left(x_{2}, x_{2}\right)\right] \\
& \preccurlyeq k\left[d\left(x_{1}, x_{2}\right)+d\left(x_{2}, x_{3}\right)\right] \\
& \preccurlyeq \frac{k}{1-k} d\left(x_{1}, x_{2}\right) .
\end{aligned}
$$

By mathematical induction we construct a sequence $\left\{x_{n}\right\}$ in $X$ such that

$$
d\left(x_{n}, x_{n+1}\right) \preccurlyeq \frac{k}{1-k} d\left(x_{n-1}, x_{n}\right) \quad \text { for } n=0,1,2,3, \ldots
$$


If $\eta=\frac{k}{1-k}$, then $\eta<1$, and we have

$$
d\left(x_{n}, x_{n+1}\right) \preccurlyeq \eta d\left(x_{n-1}, x_{n}\right) \prec \eta^{2} d\left(x_{n-2}, x_{n-3}\right) \prec \cdots \prec \eta^{n} d\left(x_{0}, x_{1}\right) .
$$

Now, for $m>n$, we have

$$
d\left(x_{n}, x_{m}\right) \preccurlyeq \frac{\eta^{n}}{1-\eta} d\left(x_{0}, x_{1}\right) .
$$

Since $\eta^{n} \rightarrow 0$ as $n \rightarrow \infty$, this gives us $\frac{\eta^{n}}{1-\eta} d\left(x_{0}, x_{1}\right) \rightarrow \theta$ in the locally convex space $\mathbb{E}$ as $n \rightarrow \infty$. Now, according to (PT7) and (PT1), we can conclude that for every $c \in \mathbb{E}$ with $\theta \ll c$, there is a natural number $n_{1}$ such that $d\left(x_{n}, x_{m}\right) \ll c$ for all $m, n \geq n_{1}$. So $\left\{x_{n}\right\}$ is a tvs-cone Cauchy sequence. Since $(X, d)$ is tvs-cone complete, therefore $\left\{x_{n}\right\}$ is tvs-cone convergent in $X$ and cone- $\lim _{n \rightarrow \infty} x_{n}=v$. That is, for every $c \in \mathbb{E}$ with $\theta \ll c$, there exists a number $k_{2}$ such that

$$
\frac{2(1+k)}{1-k} d\left(x_{n+1}, v\right) \ll c, \quad \frac{2 k}{1-k} d\left(x_{n}, v\right) \ll c \quad \text { for all } n \geq k_{2} .
$$

We now show that $v \in T v$. For this consider

$$
k\left[\ell_{x_{n}}(T v)+\ell_{v}\left(T x_{n}\right)\right] \in s\left(T x_{n}, T v\right) .
$$

It follows that

$$
k\left[\ell_{x_{n}}(T v)+\ell_{v}\left(T x_{n}\right)\right] \in s\left(x_{n+1}, T v\right), \quad \text { since } x_{n+1} \in T x_{n} .
$$

So there exists $u_{n} \in T v$ such that

$$
k\left[\ell_{x_{n}}(T v)+\ell_{v}\left(T x_{n}\right)\right] \in s\left(d\left(x_{n+1}, u_{n}\right)\right)
$$

Thus,

$$
d\left(x_{n+1}, u_{n}\right) \preccurlyeq k\left[\ell_{x_{n}}(T v)+\ell_{v}\left(T x_{n}\right)\right] .
$$

Using the fact

$$
W_{x_{n}}(T v)-\ell_{x_{n}}(T v) \subset P, \quad W_{v}\left(T x_{n}\right)-\ell_{v}\left(T x_{n}\right) \subset P,
$$

we obtain

$$
d\left(x_{n+1}, u_{n}\right) \preccurlyeq k\left[d\left(x_{n}, u_{n}\right)+d\left(v, x_{n+1}\right)\right] .
$$

Now using (3.2) we have

$$
\begin{aligned}
d\left(v, u_{n}\right) & \preccurlyeq d\left(x_{n+1}, v\right)+d\left(x_{n+1}, u_{n}\right) \\
& \preccurlyeq d\left(x_{n+1}, v\right)+k\left[d\left(x_{n}, u_{n}\right)+d\left(v, x_{n+1}\right)\right]
\end{aligned}
$$




$$
\begin{aligned}
& \preccurlyeq d\left(x_{n+1}, v\right)+k\left[d\left(x_{n}, u_{n}\right)+d\left(v, x_{n+1}\right)\right] \\
& \preccurlyeq(1+k) d\left(x_{n+1}, v\right)+k d\left(x_{n}, u_{n}\right) \\
& \preccurlyeq(1+k) d\left(x_{n+1}, v\right)+k\left[d\left(x_{n}, v\right)+d\left(v, u_{n}\right)\right] \\
& \preccurlyeq \frac{2(1+k)}{1-k} \frac{d\left(x_{n+1}, v\right)}{2}+\frac{2 k}{1-k} \frac{d\left(x_{n}, v\right)}{2} \\
& \ll \frac{c}{2}+\frac{c}{2} \ll c \text { for all } n \geq k_{2} .
\end{aligned}
$$

Therefore cone- $\lim _{n \rightarrow \infty} u_{n}=v$. Since $T v$ is closed, so $v \in T v$.

In the following we establish a Zamfirescu-type result in a tvs-cone metric space.

Theorem 3.3 Let $(X, d)$ be a complete tvs-cone metric space with a cone $P$, let $\Lambda \neq \phi$ be a collection of nonempty closed subsets of $X$, and let $T: X \rightarrow \Lambda$ be a multivalued mapping having g.l.b. property on $(X, d)$. If for $x, y \in X$ any one of the following is satisfied:

(i) $k(s(d(x, y))) \in s(T x, T y)$ for $0 \leq k<1$;

(ii) $k[d(x, T x)+d(y, T y)] \in s(T x, T y) \quad$ for $0 \leq k<\frac{1}{2}$;

(iii) $k[d(x, T y)+d(y, T x)] \in s(T x, T y) \quad$ for $0 \leq k<\frac{1}{2}$;

then $T$ has a fixed point in $X$.

Proof (i): A special case of [39] when $\varphi(d(x, y))=k<1$.

(ii): As $d(x, T x), d(y, T y) \in L_{X}(T)$.

Put $l_{x}(T x)=d(x, T x), l_{y}(T y)=d(y, T y)$, then for all $x, y \in X$

$$
k\left[l_{x}(T x)+l_{y}(T y)\right] \in s(T x, T y)
$$

Now, by Theorem 3.1, $T$ has a fixed point in $X$.

(iii): Put $l_{x}(T y)=d(x, T y), l_{y}(T x)=d(y, T x)$, then for all $x, y \in X$

$$
k\left[l_{x}(T y)+l_{y}(T x)\right] \in s(T x, T y) .
$$

Now, by Theorem 3.2, $T$ has a fixed point in $X$.

Example 3.1 Let $X=[0,1]$ and let $\mathbb{E}$ be the set of all real-valued functions on $X$ which also have continuous derivatives on $X$. Then $\mathbb{E}$ is a vector space over $\mathbb{R}$ under the following operations:

$$
(x+y)(t)=x(t)+y(t), \quad(\alpha x)(t)=\alpha x(t)
$$

for all $x, y \in \mathbb{E}, \alpha \in \mathbb{R}$. Let $\tau$ be the strongest vector (locally convex) topology on $\mathbb{E}$. Then $(X, \tau)$ is a topological vector space which is not normable and is not even metrizable. Define $d: X \times X \rightarrow \mathbb{E}$ as follows:

$$
(d(x, y))(t)=|x-y| e^{t}, \quad P=\{x \in \mathbb{E}: \theta \preccurlyeq x\}, \quad \text { where } \theta(t)=0 \text { for all } t \in X \text {. }
$$


Then $(X, d)$ is a tvs-valued cone metric space. Let $T: X \rightarrow A$ be such that

$$
T x=\left[0, \frac{x}{30}\right],
$$

then

$$
W_{x}(T y)=\left\{d(x, u): u \in\left[0, \frac{y}{30}\right]\right\} .
$$

Denote $d(x, T y)$ by the greatest lower bound of $W_{x}(T y)$. Then

$$
d(x, T y)(t)= \begin{cases}0 & \text { if } x \leq \frac{y}{30} \\ \left(x-\frac{y}{30}\right) e^{t} & \text { if } x>\frac{y}{30}\end{cases}
$$

and

$$
d(x, T x)(t)=\left(\frac{29 x}{30}\right) e^{t}
$$

Moreover, if $\theta_{x y} \in \mathbb{E}$ such that

$$
\theta_{x y}(t)=\frac{|x-y|}{30} e^{t}
$$

then

$$
\begin{aligned}
s(T x, T y)=\left\{f \in \mathbb{E}: \theta_{x y}\right. & \preccurlyeq f\}, \\
\frac{d(x, T x)+d(y, T y)}{3}(t) & =\frac{1}{3}\left(\frac{29 x}{30}+\frac{29 y}{30}\right) e^{t} \\
& =\frac{1}{3}\left(x-\frac{y}{30}+y-\frac{x}{30}\right) e^{t} \\
& =\frac{d(x, T y)+d(y, T x)}{3}(t) \\
& \geq \frac{1}{3}\left(\frac{3 x}{30}+\frac{3 y}{30}\right) e^{t} \\
& \geq \frac{1}{30}(x+y) e^{t} \\
& >\frac{|x-y|}{30} e^{t}=\theta_{x y}(t) .
\end{aligned}
$$

It follows that

$$
\frac{d(x, T x)+d(y, T y)}{3}, \frac{d(y, T x)+d(x, T y)}{3} \in s(T x, T y)
$$

for all $x, y \in X$ and, similarly,

$$
\frac{d(x, y)}{30} \in s(T x, T y)
$$

Hence $T$ satisfies all the conditions of Theorem 3.3 to obtain a fixed point of $T$. 


\section{Competing interests}

The authors declare that they have no competing interests.

\section{Authors' contributions}

Both authors contributed equally and significantly in writing this paper and approved the final manuscript.

\section{Acknowledgements}

The authors would like to thank the editor and the referees for their valuable comments and suggestions which improved greatly the quality of this paper.

\section{Received: 5 April 2013 Accepted: 28 June 2013 Published: 12 July 2013}

\section{References}

1. Huang, L, Zhang, X: Cone metric spaces and fixed point theorems of contractive mappings. J. Math. Anal. Appl. 332, 1468-1476 (2007)

2. Abbas, M, Jungck, G: Common fixed point results for noncommuting mappings without continuity in cone metric spaces. J. Math. Anal. Appl. 341, 416-420 (2008)

3. Abbas, M, Vetro, P, Khan, $\mathrm{SH}$ : On fixed points of Berinde's contractive mappings in cone metric spaces. Carpath. J. Math. 26(2), 121-133 (2010)

4. Agarwal, RP, Meehan, M, O'Regan, D: Fixed Point Theory and Applications. Cambridge University Press, Cambridge (2001)

5. Arshad, M, Azam, A, Vetro, P: Some common fixed point results in cone metric spaces. Fixed Point Theory Appl. 2009, Article ID 493965 (2009)

6. Azam, A, Arshad, M, Beg, I: Common fixed points of two maps in cone metric spaces. Rend. Circ. Mat. Palermo 57, 433-441 (2008)

7. Azam, A, Beg, I, Arshad, M: Fixed point in topological vector space-valued cone metric spaces. Fixed Point Theory Appl. 2010, 9 (2010)

8. Azam, A, Arshad, M, Beg, I: Existence of fixed points in complete cone metric spaces. Int. J. Mod. Math. 5(1), 91-99 (2010)

9. Azam, A: Fuzzy fixed points of fuzzy mappings via a rational inequality. Hacet. J. Math. Stat. 40(3), 421-431 (2011)

10. Ciric, L, Samet, B, Vetro, C, Abbas, M: Fixed point results for weak contractive mappings in ordered $K$-metric spaces. Fixed Point Theory 13(1), 59-72 (2012)

11. Cho, SH, Bae, JS: Fixed points and variational principle with applications to equilibrium problems. J. Korean Math. Soc 50, 95-109 (2013)

12. Cho, SH, Bae, JS: Variational principles on cone metric spaces. Int. J. Pure Appl. Math. 77, 709-718 (2012)

13. Cho, $\mathrm{SH}, \mathrm{Bae}, \mathrm{JS}, \mathrm{Na}$, KS: Fixed point theorems for multivalued contractive mappings and multivalued Caristi type mappings in cone metric spaces. Fixed Point Theory Appl. 2012, 133 (2012)

14. Di Bari, C, Vetro, P: Common fixed points in cone metric spaces for MK-pairs and L-pairs. Ars Comb. 99, 429-437 (2011)

15. Haghi, RH, Rezapour, S, Shahzad, N: Some fixed point generalizations are not real generalizations. Nonlinear Anal., Theory Methods Appl. 74(5), 1799-1803 (2011)

16. Janković, S, Kadelburg, Z, Radenović, S: On cone metric spaces. A survey. Nonlinear Anal. 74, 2591-2601 (2011)

17. Khani, M, Pourmahdian, M: On the metrizability of cone metric spaces. Topology Appl. 158(2), 190-193 (2011)

18. Li, Z, Jiang, S: On fixed point theory of monotone mappings with respect to a partial order introduced by a vector functional in cone metric spaces. Abstr. Appl. Anal. 2013, Article ID 349305 (2013)

19. Nieto, JJ, Pouso, RL, Rodríguez-López, R: Fixed point theorems in ordered abstract spaces. Proc. Am. Math. Soc. 135 2505-2517 (2007)

20. Rezapour, S: Best approximations in cone metric spaces. Math. Moravica 11, 85-88 (2007)

21. Rezapour, S, Hamlbarani, R: Some notes on paper 'Cone metric spaces and fixed point theorems of contractive mappings'. J. Math. Anal. Appl. 345, 719-724 (2008)

22. Rezapour, SH, Khandani, H, Vaezpour, SM: Efficacy of cones on topological vector spaces and application to common fixed points of multifunctions. Rend. Circ. Mat. Palermo 59, 185-197 (2010)

23. Simi, S: A note on Stone's, Baire's, Ky Fan's and Dugundji's theorem in tvs-cone metric spaces. Appl. Math. Lett. 24 999-1002 (2011)

24. Vetro, P, Azam, A, Arshad, M: Fixed point results in cone metric spaces for contractions of Zamfirescu type. Indian J. Math. 52(2), 251-261 (2010)

25. Wanga, S, Guo, B: Distance in cone metric spaces and common fixed point theorems. Appl. Math. Lett. 24, 1735-1739 (2011)

26. Al-Rawashdeh, A, Shatanawi, W, Khandaqji, M: Normed ordered and E-metric spaces. Int. J. Math. Math. Sci. 2012 Article ID 272137 (2012). doi:10.1155/2012/272137

27. Beg, I, Azam, A, Arshad, M: Common fixed points for maps on topological vector space valued cone metric spaces. Int. J. Math. Math. Sci. 2009, Article ID 560264 (2009). doi:10.1155/2009/560264

28. Chatterjea, SK: Fixed-point theorems. C. R. Acad. Bulgare Sci. 25, 727-730 (1972)

29. Zamfirescu, T: Fixed point theorems in metric spaces. Arch. Math. 23, 292-298 (1972)

30. Beg, I, Azam, A: Fixed points of asymptotically regular multivalued mappings. J. Aust. Math. Soc. 53, 313-326 (1992)

31. Berinde, V, Berinde, M: On Zamfirescu's fixed point theorem. Rev. Roum. Math. Pures Appl. 50, 443-453 (2005)

32. Ilić, D, Pavlović, V, Rakočević, V: Extensions of the Zamfirescu theorem to partial metric spaces. Math. Comput. Model. 55, 801-809 (2012)

33. Neammanee, K, Kaewkhao, A: Fixed point theorems of multi-valued Zamfirescu mapping. J. Math. Res. 2, 150-156 (2010)

34. Raphaeli, P, Pulickunnel, S: Fixed point theorems for T. Zamfirescu operators. Kragujev. J. Math. 36, 199-206 (2012)

35. Cho, SH, Bae, JS: Fixed point theorems for multivalued maps in cone metric spaces. Fixed Point Theory Appl. 2011, 87 (2011) 
36. Klim, DW: Dynamic processes and fixed points of set-valued nonlinear contractions in cone metric spaces. Nonlinear Anal. 71, 5170-5175 (2009)

37. Latif, A, Shaddad, FY: Fixed point results for multivalued maps in cone metric spaces. Fixed Point Theory Appl. 2010, Article ID 941371 (2010)

38. Rezapour, S, Haghi, RH: Fixed points of multifunctions on cone metric spaces. Numer. Funct. Anal. Optim. 30, 1-8 (2009)

39. Shatanawi, W, Rajic, VC, Radenovic, S, Al-Rawashdeh, A: Mizoguchi-Takahashi-type theorems in tvs-cone metric spaces. Fixed Point Theory Appl. 2012, 106 (2012)

doi:10.1186/1687-1812-2013-184

Cite this article as: Azam and Mehmood: Multivalued fixed point theorems in tvs-cone metric spaces. Fixed Point

Theory and Applications 2013 2013:184

Submit your manuscript to a SpringerOpen ${ }^{\circ}$ journal and benefit from:

- Convenient online submission

- Rigorous peer review

Immediate publication on acceptance

Open access: articles freely available online

- High visibility within the field

- Retaining the copyright to your article

Submit your next manuscript at $>$ springeropen.com 